\title{
Correction to: The sequence of disease-modifying therapies in relapsing multiple sclerosis: safety and immunologic considerations
}

\author{
Gabriel Pardo ${ }^{1}\left[\right.$ David E. Jones $^{2}$ D(D)
}

Published online: 23 October 2017

(C) Springer-Verlag GmbH Germany 2017

\section{Correction to: J Neurol}

DOI 10.1007/s00415-017-8594-9

Unfortunately, the online published article has errors in Table 2. The Peginterferon is listed as IM, when it should be SC.

The correct table (Table 2) is given in the following page.

The online version of the original article can be found under doi:10.1007/s00415-017-8594-9.

Gabriel Pardo

gabriel-pardo@omrf.org

David E. Jones

dj9d@hscmail.mcc.virginia.edu

1 OMRF Multiple Sclerosis Center of Excellence, Oklahoma Medical Research Foundation, 820 NE 15th Street, Oklahoma City, OK 73104, USA

2 Department of Neurology, University of Virginia School of Medicine, PO Box 800394, Charlottesville, VA 22908, USA 


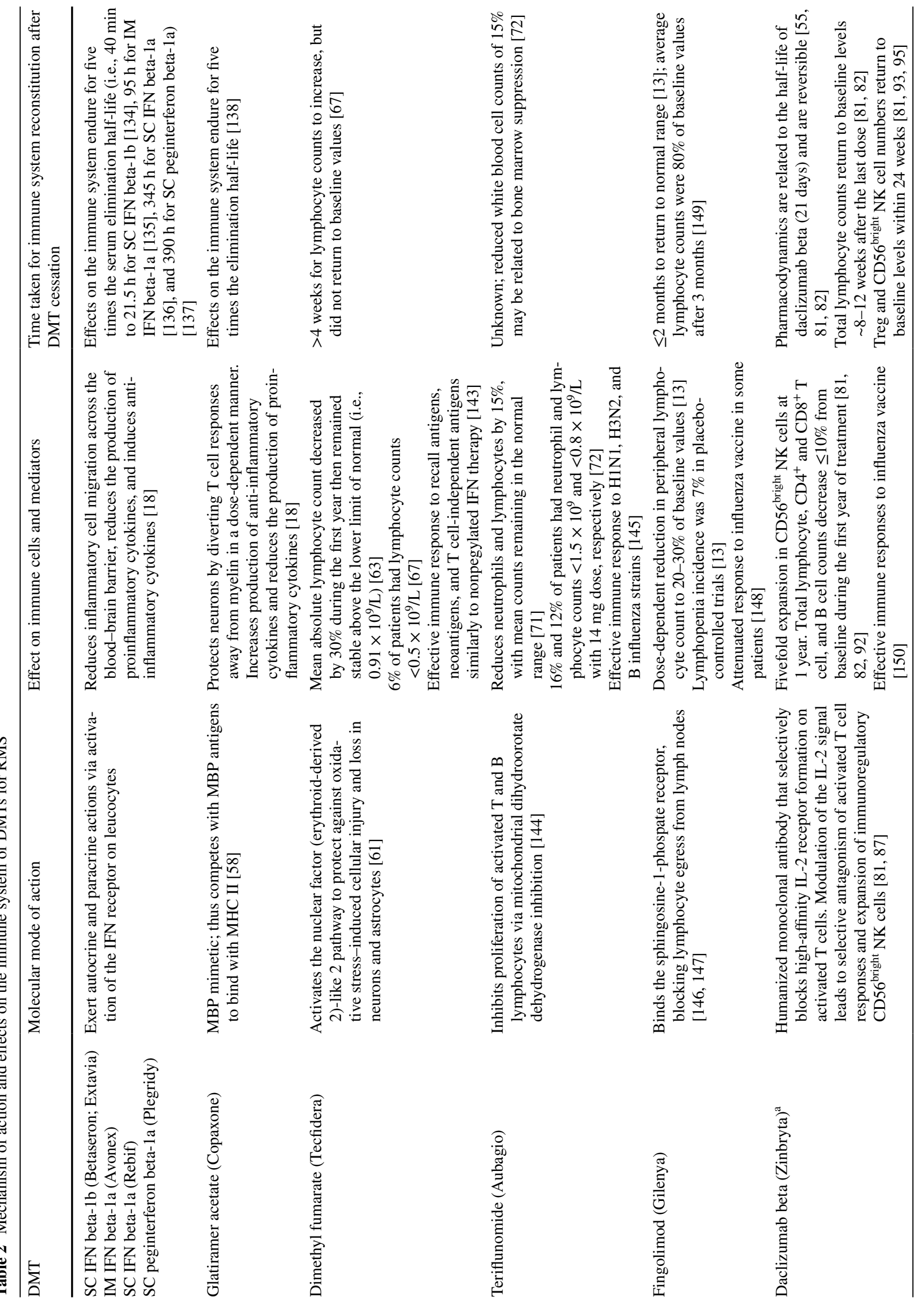




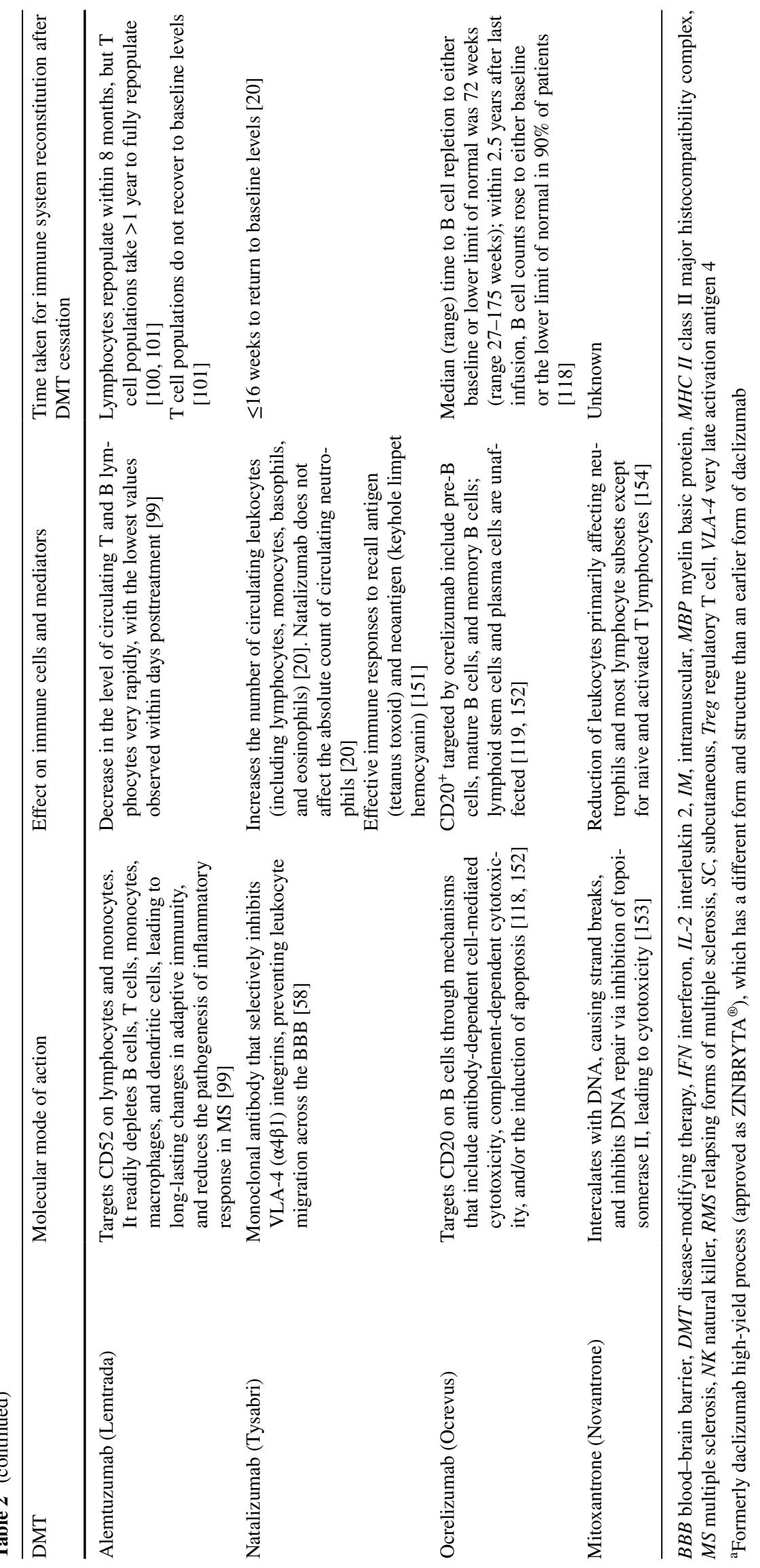

